\title{
Decline in Glucokinase Activity in the Arcuate Nucleus of Streptozotocin- Induced Diabetic Rats
}

\author{
Takashi Nishio, ${ }^{*, a}$ Yukiyasu Toyoda, ${ }^{b}$ Masayuki Hiramatsu, ${ }^{a}$ Taku ChibA, ${ }^{c}$ and Ichitomo Miwa ${ }^{b}$ \\ ${ }^{a}$ Laboratory of Neuropsychopharmacology, Graduate School of Environmental and Human Sciences, Meijo University; \\ ${ }^{b}$ Department of Pathobiochemistry, Faculty of Pharmacy, Meijo University; Tempaku-ku, Nagoya 468-8503, Japan: and \\ ${ }^{c}$ Faculty of Pharmacy, Kinjo Gakuin University; Moriyama-ku, Nagoya 463-8521, Japan. \\ Received September 13, 2005; accepted November 15, 2005
}

\begin{abstract}
Glucokinase (GK) is known to be the critical glucose sensor of pancreatic B-cells. However, the localization and functional role of GK in the brain remains to be elucidated. In this study, we measured both the activity and mRNA level of GK in the hypothalamic nuclei and the cortex of rats injected intraperitoneally with streptozotocin or vehicle. GK activity was measured by a fluorometric assay; and the GK mRNA level, by use of the realtime reverse transcription polymerase chain reaction. GK activity in vehicle-treated rats was high in the arcuate nucleus, moderate or low in the ventromedial nucleus, lateral hypothalamic area, and paraventricular nucleus, and very low in the cortex. The order of GK mRNA level was almost the same as that of GK activity. GK activity and GK mRNA level only in the arcuate nucleus of streptozotocin-treated rats at $7 \mathrm{~d}$, but not at $2 \mathrm{~d}$, after treatment were lower than those of vehicle-treated rats. The results suggest that prolonged hyperglycemia induced by diabetes decreased the activity of GK in the arcuate nucleus.
\end{abstract}

Key words glucokinase activity; glucokinase mRNA; hyperglycemia; hypothalamus; arcuate nucleus

The brain is dependent on glucose as an energy source. ${ }^{1)}$ Intricate homeostatic mechanisms have been implicated in maintaining the blood glucose concentration over a narrow physiological range. The brain, as well as the peripheral organs such as pancreas, liver, and gastrointestinal tract, is able to sense the nutritional state and secretes specific hormones to maintain metabolic homeostasis. All of these cells contain a high- $K_{\mathrm{m}}$ glucose-phosphorylating enzyme, i.e., glucokinase $(\mathrm{GK})^{2)}$

GK is a member of the hexokinase (HK) family (ATP: Dhexose 6-phosphotransferase, EC 2.7.1.1) that catalyzes the phosphorylation of glucose to glucose 6-phosphate, and is often called HK type IV. HK types I, II, and III have a high affinity $\left(K_{\mathrm{m}}=20-130 \mu \mathrm{M}\right)$ for glucose and a molecular size of about $100 \mathrm{kDa}$. In contrast, GK has a low affinity for glucose $\left(K_{\mathrm{m}}=5-10 \mathrm{~mm}\right)$, is not inhibited by physiological concentrations of glucose 6-phosphate, and has a molecular size of about $50 \mathrm{kDa}$. It is widely accepted that GK in pancreatic B-cells plays a critical role in sensing blood glucose and acts as a primary glucose sensor. ${ }^{3)}$

GK mRNA was detected in the rat brain by real-time reverse transcription polymerase chain reaction (real-time RTPCR) analysis ${ }^{4,5)}$ and reported to be localized in various hypothalamic areas, i.e. lateral hypothalamic area (LHA), ventromedial nucleus (VMN), paraventricular nucleus (PVN), dorsomedial nucleus (DMN), and arcuate nucleus (ARN), by use of the in situ hybridization technique. ${ }^{6-8)}$ The GK mRNA-expressing areas in the hypothalamus are considered to contain glucose-sensitive or glucose-responsive cells ${ }^{9-11)}$ and to play roles in feeding behavior and glucose homeostasis. ${ }^{12-14)} \mathrm{GK}$ immunoreactivity is also localized in the ependymocytes lining the ventricles and serotonin neurons in the midline medulla. ${ }^{15)}$ However, no studies have heretofore examined GK activity in each of the hypothalamic nuclei of normal or diabetic animals.

In the present study, we measured both the activity and mRNA level of GK in the hypothalamic nuclei and the brain cortex of streptozotocin (STZ)- and vehicle-treated rats.

\section{MATERIALS AND METHODS}

Injection of STZ A freshly prepared STZ solution (80 $\mathrm{mg} / \mathrm{kg}$, in $0.1 \mathrm{~m}$ sodium citrate buffer, $\mathrm{pH} 4.5$ ) or vehicle was intraperitoneally injected into male Wistar rats $(250-300 \mathrm{~g}$, Clea Japan, Tokyo, Japan). The animals were maintained individually under a regular light/dark cycle $(12 / 12 \mathrm{~h})$ and controlled room temperature $\left(21-22^{\circ} \mathrm{C}\right)$ and had ad libitum access to pelleted rat chow (CE-2, Clea Japan, Tokyo, Japan) and tap water.

Preparation of Brain Samples Rats were anesthetized by an intraperitoneal injection of pentobarbital $(50 \mathrm{mg} / \mathrm{kg})$, and then their brains were removed. Coronal brain sections were prepared at $1-\mathrm{mm}$ thickness by using a brain slicer (MBS-01C, Muromachi Kikai, Tokyo, Japan). Two sections of the hypothalamic area posterior to the bifurcation of the optic tract were obtained. Under magnification, the LHA, VMN, PVN, ARN, and the cortex were punched out with a polished 19-gauge needle ( $<1 \mathrm{~mm}$ inner diameter). Care was taken to avoid punching out the ependymal layer around the third ventricle.

Assay of HK and GK Activities Each brain sample (about $1 \mathrm{mg}$ ) was homogenized in $20 \mu \mathrm{l}$ of $200 \mathrm{~mm}$ HEPES$\mathrm{NaOH}$ buffer (pH 7.6) containing $100 \mathrm{~mm} \mathrm{KCl}, 2 \mathrm{~mm} \mathrm{MgCl}_{2}$, $1 \mathrm{~mm}$ EDTA, $1 \mathrm{~mm}$ dithiothreitol, $2 \mathrm{mg} / 1$ leupeptin, and $2 \mathrm{mg} / 1$ pepstatin A. The homogenates were centrifuged for $90 \mathrm{~min}$ at $40000 \mathrm{~g}$ at $4{ }^{\circ} \mathrm{C}$, and the supernatants taken. GK and HK activities in the supernatants were measured by a modification of our previously described method. ${ }^{16)}$ Assays were performed at $37^{\circ} \mathrm{C}$ in $200 \mathrm{~mm}$ HEPES-NaOH buffer ( $\mathrm{pH}$ 7.6) containing $100 \mathrm{~mm} \mathrm{KCl}, 8 \mathrm{~mm} \mathrm{MgCl}_{2}, 5 \mathrm{~mm}$ ATP, $0.5 \mathrm{~mm}$ NAD, $1 \mathrm{~mm}$ dithiothreitol, $0.1 \mathrm{~g} / 1$ bovine serum albumin, $1 \mathrm{U} / \mathrm{ml}$ glucose-6-phosphate dehydrogenase, 0.5 or $50 \mathrm{~mm}$ glucose, $0.5 \mathrm{~mm} 3-O$-methyl- $N$-acetyl-D-glucosamine (an inhibitor of $\mathrm{N}$-acetylglucosamine kinase that is present in the brain $^{17)}$ and phosphorylates glucose at higher glucose concentrations $\left.{ }^{18)}\right)$, and supernatant $(3.5 \mu \mathrm{l})$ in a total volume of $700 \mu \mathrm{l}$. The reaction mixture was preincubated for $3 \mathrm{~min}$, and 
the reaction was started by the addition of glucose. The rate of increase in fluorescence of NADH at excitation and emission wavelengths of 340 and $450 \mathrm{~nm}$, respectively, was recorded for about $5 \mathrm{~min}$. HK activity was measured at a glucose concentration of $0.5 \mathrm{~mm}$, and GK activity was estimated as the difference between activities at 0.5 and $50 \mathrm{~mm}$ glucose.

Fluorescence Real-Time RT-PCR for GK mRNA Brain samples (about $1 \mathrm{mg}$ ) were transferred to $100 \mu \mathrm{l}$ of TRIzol (Invitrogen, Carlsbad, CA, U.S.A.) immediately after their collection and homogenized with a Teflon pestle. Total RNA was extracted according to the protocol of the manufacturer. Single-stranded cDNA was synthesized from $1 \mu \mathrm{g}$ of total RNA with a 1st strand cDNA synthesis kit for RTPCR (Roche Diagnostics, Mannheim, Germany). GK mRNA was quantified with the ABI PRISM 7700 Sequence Detection System (Applied Biosystems, Foster, CA, U.S.A.). For detection of GK mRNA (GenBank accession no. M25807), PCR primer sets for GK (forward: 5'-CAAGCTGCACCCGAGCTT-3', reverse: 5'-TGATTCGATGAAGGTGATTTCG-3') and carboxyfluorescein (FAM)-labeled and carboxytetramethylrhodamine (TAMRA)-labeled TaqMan probes for GK (5'-TCAGCCTGCGCACACTGGCG-3') were purchased from Nihon Gene Research Laboratories (Sendai, Japan). In each well of the plate, $12.5 \mu \mathrm{l}$ of TaqMan Universal PCR Master mix (4304437; Applied Biosystems, Foster, CA, U.S.A.), $10 \mathrm{pmol}$ of primers, $1.5 \mu \mathrm{l}$ of cDNA samples, and $5.0 \mathrm{pmol}$ of GK probe were applied to give a total volume of $25 \mu \mathrm{l}$. PCR settings were as follows: 40 cycles for $15 \mathrm{~s}$ at $95^{\circ} \mathrm{C}$ and for $1 \mathrm{~min}$ at $60^{\circ} \mathrm{C}$. The amount of each mRNA was standardized by the graded dilution of highly concentrated cDNA samples from the hypothalamus. Glyceraldehyde-3-phosphate dehydrogenase (GAPDH) mRNA level, an endogenous reference, was determined from the respective standard curve by using a TaqMan Rodent GAPDH control kit (AP.BIO 4308313). Dividing each mRNA level by the GAPDH mRNA level resulted in a normalized mRNA value.

Western Blotting The ARN cytosol was separated by SDS-PAGE and transferred to a nitrocellulose membrane. Blocking, incubation with antibody, and washing for immunoblotting were performed as described previously. ${ }^{19)}$

Assessment of the Effect of STZ on GK Activity Rat liver was homogenized in 5 vol. of the buffer that was used for the homogenization of brain samples and then centrifuged for $60 \mathrm{~min}$ at $40000 \mathrm{~g}$ at $4{ }^{\circ} \mathrm{C}$. The supernatant $(90 \mu \mathrm{l})$ was mixed with $5 \mu \mathrm{l}$ of $100 \mathrm{~mm}$ glutathione and $5 \mu \mathrm{l}$ of $8 \mathrm{~mm} \mathrm{STZ}$ or vehicle $\left(\mathrm{H}_{2} \mathrm{O}\right)$ and incubated for $10 \mathrm{~min}$ at $37^{\circ} \mathrm{C}$. GK activity after incubation was spectrophotometrically assayed as described previously. ${ }^{20)}$

Assays of Insulin and Glucose Plasma insulin and glucose concentrations were measured with an insulin-ELISA kit (Morinaga Seikagaku, Tokyo, Japan) and a glucose CII test kit (Wako, Osaka, Japan), respectively.

Statistical Analysis Data were expressed as means S.D. The unpaired Student's $t$-test with Aspin-Welch correction was used to establish statistical significance.

\section{RESULTS}

The difference between glucose phosphorylation activity at $0.5 \mathrm{~mm}$ glucose and that at $50 \mathrm{~mm}$ glucose in the hypothalamus and the cortex of normal rats was lower by 30 and
$10 \%$, respectively, when measured in the presence of $0.5 \mathrm{~mm}$ 3-O-methyl- $N$-acetyl-D-glucosamine than when measured in the absence of the hexosamine (data not shown). This result suggests that the use of the hexosamine, an $\mathrm{N}$-acetylglucosamine kinase inhibitor, is indispensable for the accurate assay of GK activity in the hypothalamus and the cortex.

We examined the effect of STZ injection on GK activity and GK mRNA level, as well as on plasma glucose and insulin concentrations, at both 2 and $7 \mathrm{~d}$ after the injection. The plasma glucose of STZ-treated rats was markedly higher than that of the vehicle-treated rats at both 2 and $7 \mathrm{~d}$ after treatment, and vice versa for the plasma insulin (Table 1). GK activity in the ARN of STZ-treated rats was significantly lower than that of vehicle-treated rats at $7 \mathrm{~d}$ after the treatment (Fig. 1B), whereas there was no such difference at $2 \mathrm{~d}$ after it (Fig. 1A). STZ treatment did not affect GK activity in other brain areas at either 2 or $7 \mathrm{~d}$ posttreatment (Figs. 1A, B). A similar result was obtained as to the effect of STZ treatment on the GK mRNA level (Figs. 1C, D). We attempted to compare GK protein levels in the ARN between STZ-treated and untreated rats by Western blotting, but were unable to detect a

Table 1. Plasma Glucose and Insulin Concentrations in Vehicle- and STZTreated Rats at 2 and $7 \mathrm{~d}$ after Treatment

\begin{tabular}{|c|c|c|c|c|}
\hline & \multicolumn{2}{|c|}{ Vehicle-treated } & \multicolumn{2}{|c|}{ STZ-treated } \\
\hline & $2 \mathrm{~d}$ & $7 d$ & $2 \mathrm{~d}$ & $7 d$ \\
\hline Glucose (mм) & $8.3 \pm 1.0$ & $8.8 \pm 1.0$ & $26.1 \pm 1.0$ & $27.3 \pm 2.4$ \\
\hline Insulin (pm) & $565 \pm 114$ & $545 \pm 144$ & $67.7 \pm 8.7$ & $66.3 \pm 5.8$ \\
\hline
\end{tabular}

Values are means \pm S.D. of 4 animals.
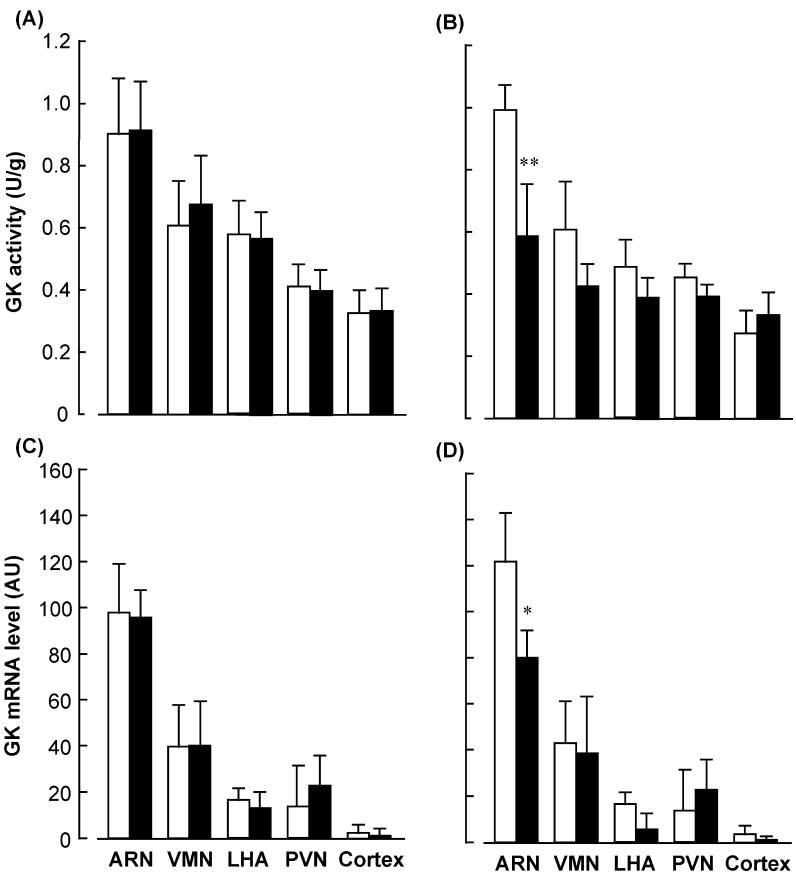

(D)

Fig. 1. GK Activity and GK mRNA Level in the Hypothalamic Nuclei and the Cortex of Vehicle- and STZ-Treated Rats

GK activity (A, B) and GK mRNA level (C, D) were measured at 2 (A, C) and $7 \mathrm{~d}$ (B, D) after an intraperitoneal injection of vehicle (open columns) or STZ solution (filled columns). ARN, arcuate nucleus; VMN, ventromedial nucleus; LHA, lateral hypothalamic area; PVN, paraventricular nucleus. GK mRNA level is expressed as an arbitrary unit (AU). Data are means \pm S.D. from 4 experiments. $* p<0.05, * * p<0.01$ compared with vehicle-treated rats. 


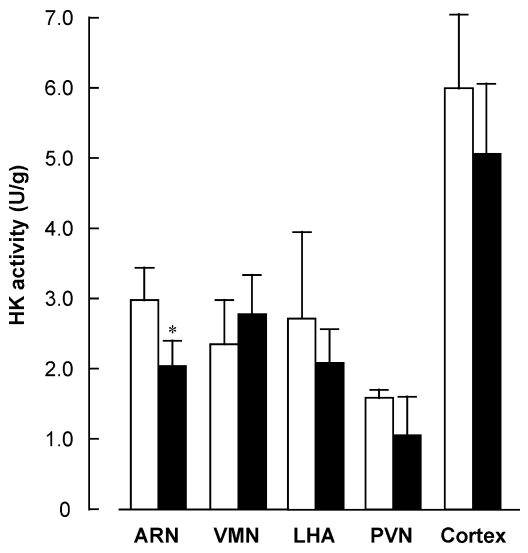

Fig. 2. HK Activity in the Hypothalamic Nuclei and Cortex of Vehicleand STZ-Treated Rats at $7 \mathrm{~d}$ after Treatment

Open columns, vehicle-treated rats; filled columns, STZ-treated rats. See the legend of Fig. 1 for abbreviations. Data are means \pm S.D. from 4 experiments. $* p<0.05$ compared with vehicle-treated rats.

band of GK in any of the ARN samples probably due to extremely low level of GK expression in the ARN. HK activity only in the ARN was decreased at $7 \mathrm{~d}$ after STZ treatment (Fig. 2), whereas the treatment did not affect HK activity in all the brain areas at $2 \mathrm{~d}$ posttreatment (data not shown). GK activity in the cortex relative to the hypothalamic nuclei was low, whereas HK activity was higher in the former than in the latter (Fig. 2).

We examined the possibility of GK-inactivating action of STZ, which we used as the diabetogenic substance in this study. STZ did not affect GK activity when the enzyme was incubated with STZ at $0.4 \mathrm{~mm}$ (a possible maximum tissue concentration of the substance on the assumption that the drug is distributed evenly in all intracellular and extracellular fluids) for $10 \mathrm{~min}$ at $37^{\circ} \mathrm{C}$ in the presence of $5 \mathrm{~mm}$ glutathione (data not shown).

\section{DISCUSSION}

Previous studies reported the existence of GK mRNA in hypothalamic nuclei as shown by using real-time RT-PCR ${ }^{4,5}$ or the in situ hybridization technique. ${ }^{6-8)}$ However, GK activity in the hypothalamic nuclei had not been heretofore reported. Our study is the first to measure GK activity in hypothalamic nuclei. It should be noted that the use of 3$O$-methyl- $N$-acetyl-D-glucosamine for the block of glucose phosphorylation by $N$-acetylglucosamine kinase at a high glucose concentration $(50 \mathrm{~mm})$ is necessary to perform an accurate assay of GK activity in hypothalamic nuclei.

In previous reports, the GK mRNA level measured by real-time RT-PCR or the in situ hybridization technique was higher in the ARN than in other hypothalamic nuclei and was very low in the cortex. ${ }^{4-8)}$ The order of GK activity as well as GK mRNA level in the hypothalamic nuclei of normal (vehicle-treated) rats (Fig. 1) is in good agreement with that of GK mRNA levels found in previous studies, suggesting that our assay of GK activity and GK mRNA level in hypothalamic nuclei is reliable.

Our original purpose for injecting STZ was to induce diabetes and to examine the effect of diabetic hyperglycemia on hypothalamic GK activity and GK mRNA level. It would be possible, however, that STZ destroys not only pancreatic Bcells but also some of the hypothalamic neurons. Since STZ is an unstable compound, the GK activity and GK mRNA level in the hypothalamus would be affected within a day provided that STZ destroys neurons. Therefore, we examined the effect of STZ injection on GK activity and GK mRNA level, as well as on plasma glucose and insulin concentrations, at not only $7 \mathrm{~d}$ but also $2 \mathrm{~d}$ after the injection. Both GK activity and GK mRNA level decreased only in the ARN among various hypothalamic nuclei in STZ-treated rats relative to that in vehicle-treated rats at $7 \mathrm{~d}$ after treatment (Fig. 1). At $2 \mathrm{~d}$ after STZ treatment, however, no effect of the treatment on GK activity and GK mRNA level was observed, whereas the treatment increased plasma glucose levels and decreased plasma insulin levels. These results combined with the fact that STZ per se did not affect GK activity suggest that it is unlikely that STZ destroys neurons in the ARN as it does pancreatic B-cells. In addition, they suggest that prolonged hyperglycemia induces a decline in the amount of GK in the ARN.

The ARN is believed to function as a feeding center. ${ }^{21)}$ Neuropeptide Y neurons that are present in the ARN and express GK mRNA ${ }^{12}$ are known to be glucose-inhibited neurons and to stimulate feeding when activated by lowering in the blood glucose concentration. ${ }^{22}$ It is likely that the decrease in GK activity in the ARN at $7 \mathrm{~d}$ after STZ treatment in the present study elevates the threshold for glucose of neuropeptide $\mathrm{Y}$ neurons and thus induces hyperphagia, a known feature of STZ-diabetic rats.

The low GK and high HK activities in the cortex (Figs. 1, 2) were in good agreement with the data in a previous paper. $^{23)}$ This high distribution of HK in the cortex may be related to the finding by Dunn-Meynell et al. ${ }^{12)}$ that in the cortex, where the glia/neuron ratio is higher than in the hypothalamic nuclei, HK is present in both neuronal and glial cells, but GK is expressed only in neuronal cells.

Interestingly, an injection of alloxan at a dose of $120 \mu \mathrm{g}$, a cytotoxic dose, ${ }^{13)}$ into the third ventricle of rats caused a significant decline in GK and $\mathrm{HK}$ activities only in the ARN among various hypothalamic nuclei at $3 \mathrm{~d}$ after the injection (T. Nishio, Y. Toyoda, M. Hiramatsu, and I. Miwa, unpublished data). Alloxan at cytotoxic doses induces cell death presumably through the production of reactive oxygen species. $^{24,25)}$ Prolonged hyperglycemia caused by diabetes is known to induce oxidative stress in various tissues. ${ }^{26,27)}$ Taken together, the available data suggest that neurons in the ARN are susceptible to oxidative stress induced by hyperglycemia in the diabetic state; and thus the death of the neurons takes place resulting in the decline in GK and $\mathrm{HK}$ activities as well as GK mRNA level in the ARN. However, there may be other possibilities: for instance, it is possible that hyperglycemia downregulates the expression of GK and HK in the ARN by some yet unknown mechanism. Conceivable implications of the decline in GK activity in the ARN on feeding behavior and glucose homeostasis remain to be studied.

Acknowledgements We are grateful to $\mathrm{T}$. Taguchi (Meijo University), S. Tsukahara (National Institute for Environmental Studies), T. Yada, and F. Maekawa (Jichi Medical School) for valuable discussion, and M. Hoshino and M. Tanahashi for their technical assistance. 


\section{REFERENCES}

1) Sokoloff L., Reivich M., Kennedy C., Des Rosiers M. H., Patlak C. S. Pettigrew K. D., Sakurada O., Shinohara M., J. Neurochem., 28, 897916 (1977).

2) Matschinsky F. M., Ellerman J. E., J. Biol. Chem., 243, 2730-2736 (1968).

3) Matschinsky F. M., Diabetes, 39, 647-652 (1990).

4) Li B., Xi X., Roane D. S., Ryan D. H., Martin R. J., Brain Res. Mol. Brain Res., 113, 139-142 (2003).

5) Lynch R. M., Tompkins L. S., Brooks H. L., Dunn-Meynell A. A., Levin B. E., Diabetes, 49, 693-700 (2000).

6) Alvarez E., Roncero I., Chowen J. A., Thorens B., Blazquez E., J. Neurochem., 66, 920-927 (1996).

7) Jetton T. L., Liang Y., Pettepher C. C., Zimmerman E. C., Cox F. G., Horvath K., Matschinsky F. M., Magnuson M. A., J. Biol. Chem., 269, 3641-3654 (1994).

8) Navarro M., Rodriquez de Fonseca F., Alvarez E., Chowen J. A., Zueco J. A., Gomez R., Eng J., Blazquez E., J. Neurochem., 67, 1982-1991 (1996).

9) Muller Y. L., Reitstetter R., Yool A. J., J. Neurosci., 18, 16-25 (1998).

10) Ono T., Nishino H., Fukuda M., Sasaki K., Muramoto K., Oomura Y., Brain Res., 232, $494-499$ (1982).

11) Silver I. A., Erecinska M., J. Neurophysiol., 79, 1733-1745 (1998).

12) Dunn-Meynell A. A., Routh V. H., Kang L., Gaspers L., Levin B. E., Diabetes, 51, 2056-2065 (2002).

13) Sanders N. M., Dunn-Meynell A. A., Levin B. E., Diabetes, 53 ,
1230 - 1236 (2004).

14) Schuit F. C., Huypens P., Heimberg H., Pipeleers D. G., Diabetes, 50, $1-11(2001)$

15) Maekawa F., Toyoda Y., Torii N., Miwa I., Thompson R. C., Foster D. L., Tsukahara S., Tsukamura H., Maeda K., Endocrinology, 141 375-384 (2000)

16) Miwa I., Mita Y., Murata T., Okuda J., Sugiura M., Hamada Y., Chiba T., Enz. Prot., 48, 135-142 (1995).

17) Bachelard H. S., Nature (London), 215, 959-960 (1967).

18) Salas J., Salas M., Vinuela E., Sols A., J. Biol. Chem., 240, 1014 1018 (1965).

19) Miwa I., Mitsuyama S., Toyoda Y., Nonogaki T., Aoki S., Okuda J., Biochem. Int., 22, $759-767$ (1990).

20) Hara H., Miwa I., Okuda J., Chem. Pharm. Bull., 34, 4731-4737 (1986).

21) Jhanwar-Uniyal M., Beck B., Jhanwar Y. S., Burlet C., Leibowitz S. F., Brain Res., 631, 97-106 (1993).

22) Muroya S., Yada T., Shioda S., Takigawa M., Neurosci. Lett., 264, 113-116 (1999).

23) Roncero I., Alvarez E., Vazquez P., Blazquez E., J. Neurochem., 74, 1848-1857 (2000).

24) Yamamoto H., Uchigata Y., Okamoto H., Nature (London), 294, 284-286 (1981)

25) Takasu N., Asawa T., Komiya I., Nagasawa Y., Yamada T., J. Biol. Chem., 266, 2112-2114 (1991).

26) Oberley L. W., Free Radic. Biol. Med., 5, 113-124 (1988)

27) Baynes J. W., Thorpe S. R., Diabetes, 48, 1-9 (1999). 